\title{
Erratum to: Effect of Crystallinity on Electrostatic Charging in Dry Powder Inhaler Formulations
}

\author{
Jennifer Wong' ' Philip Chi Lip Kwok ${ }^{2}$ - Tim Noakes ${ }^{3}$ - Ali Fathi ${ }^{4}$ - Fariba Dehghani ${ }^{4}$.
} Hak-Kim Chan'

Published online: 9 March 2017

(C) Springer Science+Business Media New York 2017

\section{Erratum to: Pharm Res}

\section{DOI I0.1007/s | | 095-0|3-1270-6}

There is an error in the published article (Volume 31, Number 7, pp. 1656-1664).

The error occurs in 'Table III Specific Charges (nC/g) of amorphous and crystalline salbutamol sulfate (SS) generated by tumbling in containers made of different materials' on page 1663.

The specific columns affected are 'Container material' and 'Work function' where the values for 'Nylon' and '4.4' should have 'Specific charge (nC/g)' values of '26.49 (5.31)' and '$13.07(0.90)$ '. On the other hand, 'Polyvinyl chloride' and '5.1' should have 'Specific charge (nC/g)' values of '18.62 (5.09)' and ' $-5.65(1.76)$ '.

The online version of the original article can be found at http://dx.doi.org/l0. | 007/s | | 095-0 |3-1270-6.

\section{Hak-Kim Chan}

kim.chan@sydney.edu.au

Advanced Drug Delivery Group, Faculty of

Pharmacy, The University of Sydney, Sydney, New South Wales, Australia

2 Department of Pharmacology and Pharmacy Li Ka Shing Faculty of Medicine, The University of Hong Kong, Hong Kong, SAR, China

3 Mexichem UK Limited, The Heath Business and Technical Park, Runcorn, Cheshire, WA7 4QX, UK

4 School of Chemical and Biomolecular Engineering, The University of Sydney, Sydney, New South Wales, Australia
The corrected Table appears below.

Table III Specific Charges ( $\mathrm{nC} / \mathrm{g}$ ) of Amorphous and Crystalline Salbutamol Sulphate (SS) Generated by Tumbling in Containers Made of Different Materials

\begin{tabular}{|c|c|c|c|c|}
\hline & \multirow{2}{*}{$\begin{array}{l}\text { Container } \\
\text { material }\end{array}$} & \multirow{2}{*}{$\begin{array}{l}\text { Work } \\
\text { Function } \\
(\mathrm{eV})^{\mathrm{a}}\end{array}$} & \multicolumn{2}{|c|}{ Specific Charge (nC/g) } \\
\hline & & & Amorphous SS & Crystalline SS \\
\hline \multirow[t]{4}{*}{ Non-metal } & Polyethylene & 4.9 & $15.02(2.14)$ & $-4.45(4.19)$ \\
\hline & $\begin{array}{l}\text { Polyvinyl } \\
\text { chloride }\end{array}$ & 5.1 & | $8.62(5.09)$ & $-5.65(1.76)$ \\
\hline & Nylon & 4.4 & $26.49(5.31)$ & $-13.07(0.90)$ \\
\hline & Teflon & 5.8 & $26.61(1.85)$ & $11.88(2.52)$ \\
\hline Metal & Stainless steel & 5.15 & $26.22(5.94)$ & $-12.10(2.52)$ \\
\hline
\end{tabular}

Data presented as mean \pm standard deviation $(n=8)$

${ }^{a}$ Work function values were obtained from $(10)$ 